\title{
Multivariate approach of soil attributes on the characterization of land use in the southern Brazilian Amazon
}

\author{
Marco Antonio Camillo de Carvalho, ${ }^{\mathrm{a}, *}$, Alan Rodrigo Panosso ${ }^{\mathrm{b}}$, \\ Elisabethe Emilia Ribeiro Teixeira ${ }^{\mathrm{a}}$, Elton Gean Araújo $^{\mathrm{c}}$, Vivian Aparecida Brancaglioni ${ }^{\mathrm{d}}$, \\ Rivanildo Dallacort ${ }^{\mathrm{a}}$ \\ ${ }^{a}$ UNEMAT - Mato Grosso State University, Departament of Agronomy, Rodovia MT 208, km 145, Jardim Tropical, Alta Floreta, Mato Grosso, Brazil \\ ${ }^{\mathrm{b}}$ UNESP - Universidade Estadual Paulista, Departament of Exact Science, Via de acesso Prof. Paulo D. Castellane s/n., 14884-900, Jaboticabal, São Paulo, Brazil \\ ${ }^{\mathrm{c}}$ UFMS - Federal University of Mato Grosso do Sul, Avenida Pedro Pedrossian, 725, Bairro Universitário, 79500-000, Paranaíba, MS, Brazil \\ ' USP/ESALQ University of São Paulo "Luiz de Queiroz" College of Agriculture, Department of Exact Science, Av. Pádua Dias, 11, CEP, 13418-260, Piracicaba-SP, Brazil
}

\section{A R T I C L E I N F O}

\section{Keywords:}

Amazonian agroecosystems

Soil quality

Structural equation analysis

\begin{abstract}
A B S T R A C T
Determination of physical, chemical and biological attributes with individual analyses is inadequate for improving the understanding of soil conditions as a function of land-use change (LUC) in comparison to the natural state of soil. For a more accurate soil condition diagnostic, it is necessary to consider various indicators related to these characteristics, which requires the use of multivariate statistical analysis. The aim of this work was to characterize, through multivariate analysis, different types of LUCs in an Oxisol as a function of the physical, chemical and biological attributes and to clarify the relationship of these attributes with the quality of the soil in comparison to these attributes in natural soil conditions, in the southern Amazon in Brazil. The land uses evaluated in the municipality of Alta Floresta, state of Mato Grosso (MT), Brazil, were native amazon forest (ma), degraded pasture (pd), managed renewed pasture (pn), permanent preservation area in recovery (app), crop area (rice), forage sugarcane (ca) and reforested area with eucalyptus (eu). To characterize the physical and chemical soil attributes, samples were collected in each land-use area, at depths of $0-0.10$ and $0.10-0.20 \mathrm{~m}$, and the determination of soil microbial activity (biological attributes) was evaluated at a depth of $0-0.10 \mathrm{~m}$. The interrelationship between the analyzed attributes was described by multivariate techniques, which included hierarchical and non-hierarchical cluster analyses, principal component analysis, canonical correlation, and structural equation modeling. The multivariate approach for the analysis of soil attribute data was efficient in the identification of anthropogenic actions on areas in comparison to natural conditions. Together, the cluster analysis and principal components analysis identified two groups that differed mainly in terms of anthropic operations of soil tillage and liming. The land use that was most similar to the natural condition was degraded pasture, which was mainly due to $\mathrm{K}$ and $\mathrm{H}+\mathrm{Al}$ contents, soil microporosity and soil basal respiration. Structural equation modeling indicated that the latent factor soil chemical attributes had three times greater interference $(-0.5828)$ than the latent factor soil physical attributes $(0.1735)$ on the latent factor soil biological attributes. Therefore, anthropic actions, especially the liming, modified soil acidity conditions, affecting the microorganisms of its flora and changing the native fungal community of the soil that was evaluated.
\end{abstract}

\section{Introduction}

The loss of native vegetation coverage, land-use change (LUC), and the inappropriate use of soil have led to the degradation of natural resources and reduction of soil quality related to its physical, chemical and biological attributes (Rojas et al., 2016). The economic and social pressure for food production, as well as the inappropriate and unplanned exploitation of natural resources, have caused degradation in large areas, mainly through the inadequate conversion of natural environments into agricultural areas (Fonseca et al., 2007; Rojas et al., 2016). The main impact of LUC is on in the soils, which are directly responsible for the sustainability and productivity of natural and agricultural ecosystems (Castilho et al., 2016; Novak et al., 2017; Sanabria et al., 2016).

Studying the physical, chemical and biological attributes of soil in different applications and comparing these attributes to those in areas

\footnotetext{
* Corresponding author.

E-mail address: marcocarvalho@unemat.br (M.A.C. de Carvalho).
} 
without anthropic action makes it possible to quantify the magnitude of the changes that have occurred due to different models of exploitation (Brookes, 1995; Gomes et al., 2016). According to Reicher et al. (2009), based on the sensitivity of these attributes, it is possible to establish the occurrence of degradation or improvement of soil quality compared to soil in a non-anthropized environment. According to Doran et al. (1994), good levels of these attributes provide ideal conditions for the growth and development of plants and favor maintenance of diversity of the organisms that exist in the soil. Currently, there are several techniques and methodologies used to evaluate soil microbial activity, such as enzymatic activity and genetic fingerprinting. However, techniques that characterize soil basal respiration (SBR) and carbon levels of microbial biomass (MBC) are preferable due to the ease of their application and lower costs; hence, these techniques are considered as important tools in understanding changes in soil organic compartments.

In addition, it should be stressed that existing interrelations among the physical, chemical and biological attributes control the processes and aspects related to variance with time and space. Therefore, changes in the structure of the soil and in its biological activity and fertility may have impacts on agroecosystems, such as damage to soil quality and productivity of crops (Brookes, 1995). Knowing the modifications that occurred in the soil caused by its use provides information that can help adapt management practices to enable crop output to be increased, which thereby ensures the sustainability and conservation of the agroecosystem.

Considering the soil as a complex system, resulting from the interaction of geological, topographical and climate factors, among others, which together form indicators that characterize the soil, it is possible to use multivariate analysis techniques to more efficiently explore the correlations among these variables and determine those that contribute more to soil characterization and/or soil changes (Gong et al., 2015; Khaledian et al., 2017; Pragana et al., 2012; Rojas et al., 2016). Nazmi (2013) used multiple linear regression models and equation modeling with the aim of correlating latent factors (factors that are not observable on the field but are associated with correlated attributes observed on the field) and determining the influence of these factors on the physical, chemical and production attributes of wheat. It was concluded that the measurements of physical and chemical attributes were statistically significant for predicting and understanding the components of wheat production using regression and structural models. Therefore, multivariate techniques are promising for studies of land-use and management practices that influence the quality and health of the soils. Research with the aim of understanding indicators of soil quality that best explain the changes that have occurred due to soil use may contribute to enhancing soil quality if appropriate practices are employed. Given this context, the objective of this work was to characterize different soil uses in the southern Amazon, as a function of the physical, chemical and biological attributes to identify which key properties can be used to characterize the soil, as well as to establish the interrelation of the soil attributes with soil' quality and natural conditions of the systems, using multivariate techniques, mainly structural equation modeling.

\section{Materials and methods}

\subsection{Area of study}

The field experiment was carried out in the rural property named the Maringá Farm, located in Alta Floresta, on the MT 206 road km 165, whose geographical coordinates are $9^{\circ} 50^{\prime} 23.86^{\prime \prime}$ south latitude and $56^{\circ}$ $13^{\prime} 22.89^{\prime \prime}$ west longitude and is located at $280 \mathrm{~m}$ above sea level (Fig. 1). The region has a rainy tropical climate, type Am according to the Köppen classification, with short dry periods and long rainy periods, temperatures range from 25 to $27^{\circ} \mathrm{C}$, and the average precipitation is $2243 \mathrm{~mm}$. The soils of the experimental areas are classified as Oxisols. The terrain was classified as moderately flat.
The land uses selected were the following: native forest area (ma), characterized as dense ombrophylous forest, with an area of 11.5 ha; degraded pasture (pd) with Brachiaria brizantha since 1993 and with 5 years of fertilization at $120 \mathrm{~kg} \mathrm{ha}^{-1}$ of Thermophosphate $(16.5 \%$ of $\mathrm{P}_{2} \mathrm{O}_{5}$ ), with an area of 10.5 ha; renewed pasture (pn), cultivated with Brachiaria brizantha since 2016 with an application of $150 \mathrm{~kg}$ of monoammonium-phosphate (MAP) and $3.0 \mathrm{Mg} \mathrm{ha}^{-1}$ of limestone, with an area of 26.3 ha; permanent preservation area (ppa) in recovery, which was established with Brachiaria brizantha in 1993, and in 2014, the pasture was eliminated and primary and secondary native forest species were introduced for reforestation, with an area of 5.1 ha; farming area (la), which had contained Brachiaria brizantha since 1997 but was eventually removed, with conventional soil tillage (plow) to carry out rice planting, with a seeding fertilization of $150 \mathrm{~kg} \mathrm{ha}^{-1}$ of mono amino phosphate (MAP-10\% of $\mathrm{N}$ and $50 \%$ of $\mathrm{P}_{2} \mathrm{O}_{5}$ ) and an application of $120 \mathrm{~kg} \mathrm{ha}^{-1}$ of 20-00-20 on the covering, harvest occurred in 2016/ 2017 , with an area of 22.5 ha; forage sugarcane area (ca), whose planting was performed in 2003, with an application of limestone at $2.5 \mathrm{Mg} \mathrm{ha}^{-1}$ and fertilization of $120 \mathrm{~kg} \mathrm{ha}^{-1}$ of $\mathrm{N}: \mathrm{P}_{2} \mathrm{O}_{5}: \mathrm{K}_{2} \mathrm{O}(00-20-20)$, annual covering fertilization with $120 \mathrm{~kg} \mathrm{ha}^{-1}$ of $20: 00: 20$, and previously, the area had contained Brachiaria brizantha since 1993, with an area of 7.6 ha; reforestation area (eu) with eucalyptus since 2012, without any type of fertilization or limestone application, and the area had contained Brachiaria brizantha since 1997, but it was eventually removed, with conventional soil tillage (plow), with an area of 4.5 ha (Fig. 1). An evaluation of the native forest area (Amazon Forest) was used as a reference for the analysis because it represents the conditions before anthropic actions.

\subsection{Determination of the soil's biological, physical and chemical attributes}

The collection of soil samples was made with the aid of an auger, totaling ten repetitions, at the $0-10-\mathrm{m}$ layer in each treatment. In the field, the samples were kept in styrofoam coolers with ice until their transportation to the Laboratory of Soils and Foliar Analysis of the University of Mato Grosso State - UNEMAT, Campus of Alta Floresta, where they were sieved $(2 \mathrm{~mm})$ and kept under refrigeration until the analyses were made. The analysis was based on the procedures proposed by Silva et al. (2007a) for determining the soil basal respiration (SBR), and the determination of its microbial biomass carbon (MBC) was performed according to the recommendations of Silva et al. (2007b).

The analyses were made at the Laboratory of Soils and Foliar Analysis at the University of Mato Grosso State - UNEMAT, Campus of Alta Floresta. To determine the porosity of the soil, the tension table method was employed, which was adapted from Kiehl (1979). The nondeformed soil samples were properly prepared (the inner surface of the ring was protected with a tissue that was slightly larger than the ring's diameter, such that the excess bent over the ring's surface and was tied with an elastic band) and saturated through the gradual elevation of a water blade on a tray, until it attained $2 / 3$ of the samples' height, according to Embrapa (1997). Then, the following analysis procedures were conducted. After being saturated, the samples were placed upon the tension table, the level vial was lowered to the level of suction corresponding to $0.60 \mathrm{~m}$ of water column height $(-0.006 \mathrm{MPa})$, and then, water from the macropores was removed (\% of pores with diameter of $0.05 \mathrm{~mm}$ ). After being weighed, before (saturated) and after the table (until draining stopped, when a constant weight is attained for the sample), the volume of the macropores was determined using Eq. (1) (EMBRAPA, 1997).

$M a=\left(\frac{W \text { saturated }-W \text { after tension table }}{\text { Total volume }}\right) \times 100$

After removing the water from the macropores (\% of pores with diameter of $0.05 \mathrm{~mm}$ ), the samples were dried in greenhouse circulation 


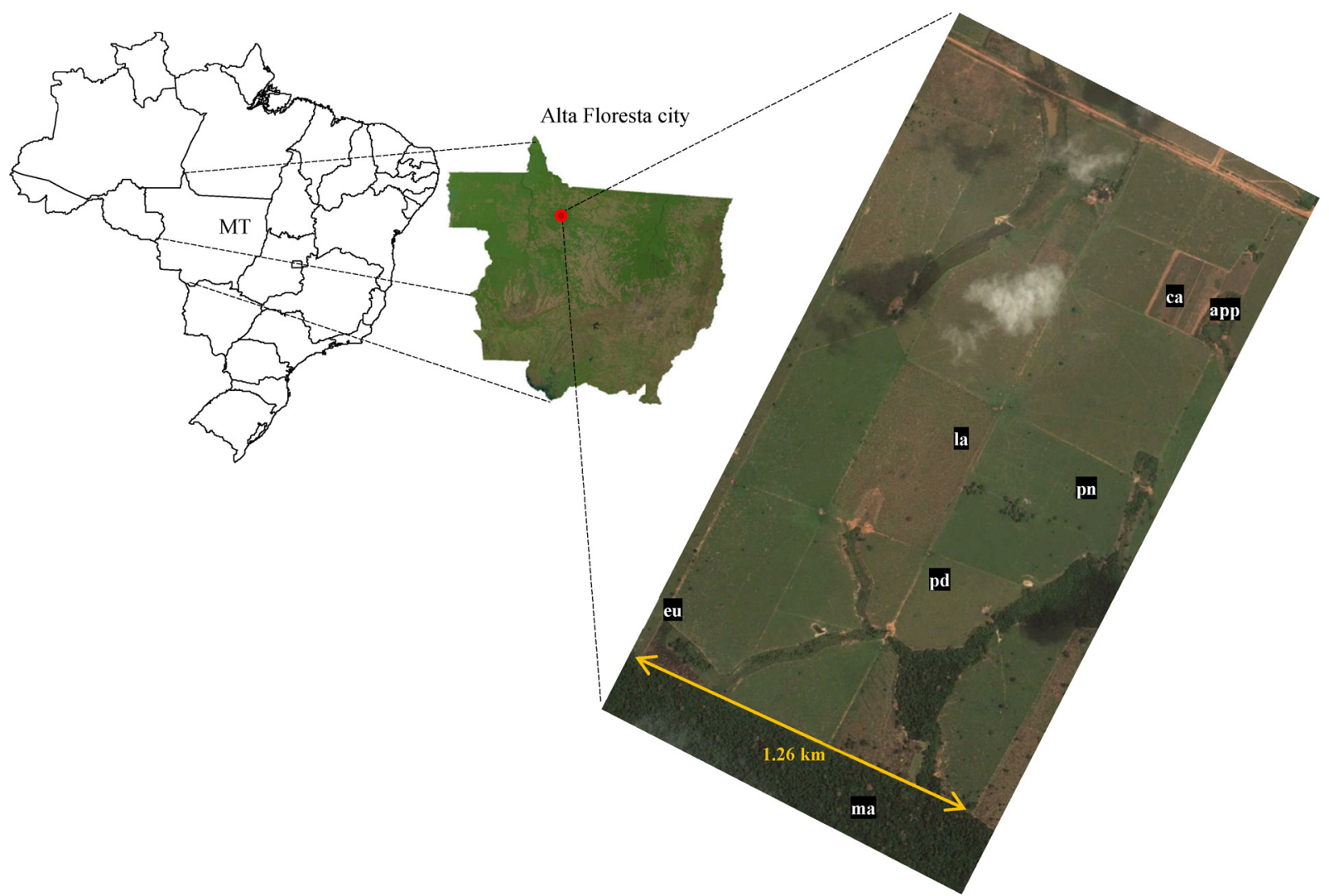

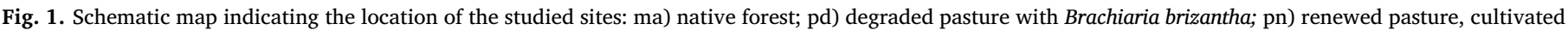
with Brachiaria brizantha; app) permanent preservation area in recovery; la) rice planting; ca) forage sugarcane and eu) reforestation area with eucalyptus.

at $105^{\circ} \mathrm{C}$ for $24 \mathrm{~h}$. After being weighed, before (drained at $-0.006 \mathrm{MPa}$ ) and after (dried in greenhouse), the volume of the micropores was obtained using Eq. (2)(EMBRAPA, 1997).

$M i=\left(\frac{W \text { after tension table }-W \text { dried }}{\text { Total volume }}\right) \times 100$

Through Eq. (3), the total volume of the pores in the soil (\%) filled with water and/or air in the samples was determined, according to EMBRAPA (1997):

$T P V=M a+M i$

The bulk density $\left(\mathrm{g} \mathrm{cm}^{-3}\right)$ was obtained using the mass from the sample dried in greenhouse circulation at $105^{\circ} \mathrm{C}$ (subtracting the weight of the tissue, elastic band and the ring from the total weight) and the corresponding ring volume, using Eq. (4)(EMBRAPA, 1997):

$B d=\frac{W \text { dried }}{\text { ring volume }}$

The chemical attributes were analyzed at the Laboratory of Soils and Foliar Analysis of the University of Mato Grosso State - UNEMAT, Campus of Alta Floresta, according to the methodology described by EMBRAPA (1997) for the following: $\mathrm{pH}$ in $\mathrm{CaCl}_{2}$; organic matter (OM); exchangeable aluminum (Al), calcium (Ca), magnesium ( $\mathrm{Mg}$ ) and potassium (K) contents; available phosphorus $(\mathrm{P})$ and potential acidity $\left(\mathrm{H}^{+}+\mathrm{Al}^{-3}\right)$. The effective CEC, sum of the bases (bases), saturation by bases $(\mathrm{V})$ and saturation by aluminum $(\mathrm{m})$ were calculated from the analytical data. The granulometry (contents of clay, silt and sand) was determined via the densimeter method after slow-stirring for $16 \mathrm{~h}$ (Camargo et al., 1986).

\subsection{Statistical analyses}

Initially, each attribute was described through descriptive statistical analysis of the data, as well as the existence of misleading values (multivariate outliers). Subsequently, the multivariate normality hypothesis was evaluated, followed by application of the following multivariate statistical methods: principal components analysis (PCA), clustering analysis, canonical correlation analysis (CCA) and structural equation modeling (SEM).

CCA, comprising most of the attributes studied, was employed for data set reduction in linear combinations and generated scores for the first two canonical variables that explain the maximum possible total variation (Cruz and Regazzi, 1994). Unlike PCA, which aims to maximize the total explained variance, CCA aims to maximize the existing correlation of the output variable sets (Hair et al., 2005). Consider $X$ as a random vector whose dimension is $(p+q \times 1)$, with sample covariance matrix $S_{(p+q) \times(p+q)}$. Let $X^{(1)}(p \times 1)$ and $X^{(2)}(q \times 1)$ be the vectors defined as the partitions of the original vector $X$, representing a group with $p$ variables (biological attributes) and another one with $q$ (physical-chemical attributes), respectively. For the random vector $X$, the covariance matrix is represented as follows (Johnson and Wichern, 2002):

$S_{(\mathrm{p}+\mathrm{q}) \times(\mathrm{p}+\mathrm{q})}=\left[\begin{array}{ll}S_{(p \times p)}^{(11)} & S_{(p \times q)}^{(12)} \\ S_{(q \times p)}^{(21)} & S_{(q \times q)}^{(22)}\end{array}\right]$

The covariances between pairs of variables belonging to both groups, $\mathrm{X}^{(1)}$ e $\mathrm{X}^{(2)}$, are contained in $S_{(p \times q)}^{(12)}$ e $S_{(q \times p)}^{(21)}$, and the $p q$ elements that compose them measure the association between the two groups. The study of these associations occurs through canonical variables, which are constructed from linear combinations of biological variables represented by $\mathrm{U}$, and the physical-chemical ones represented by $\mathrm{V}$, which are defined as:

$\mathrm{U}=\mathrm{a}^{\mathrm{T}} \mathrm{X}^{(1)}$ 


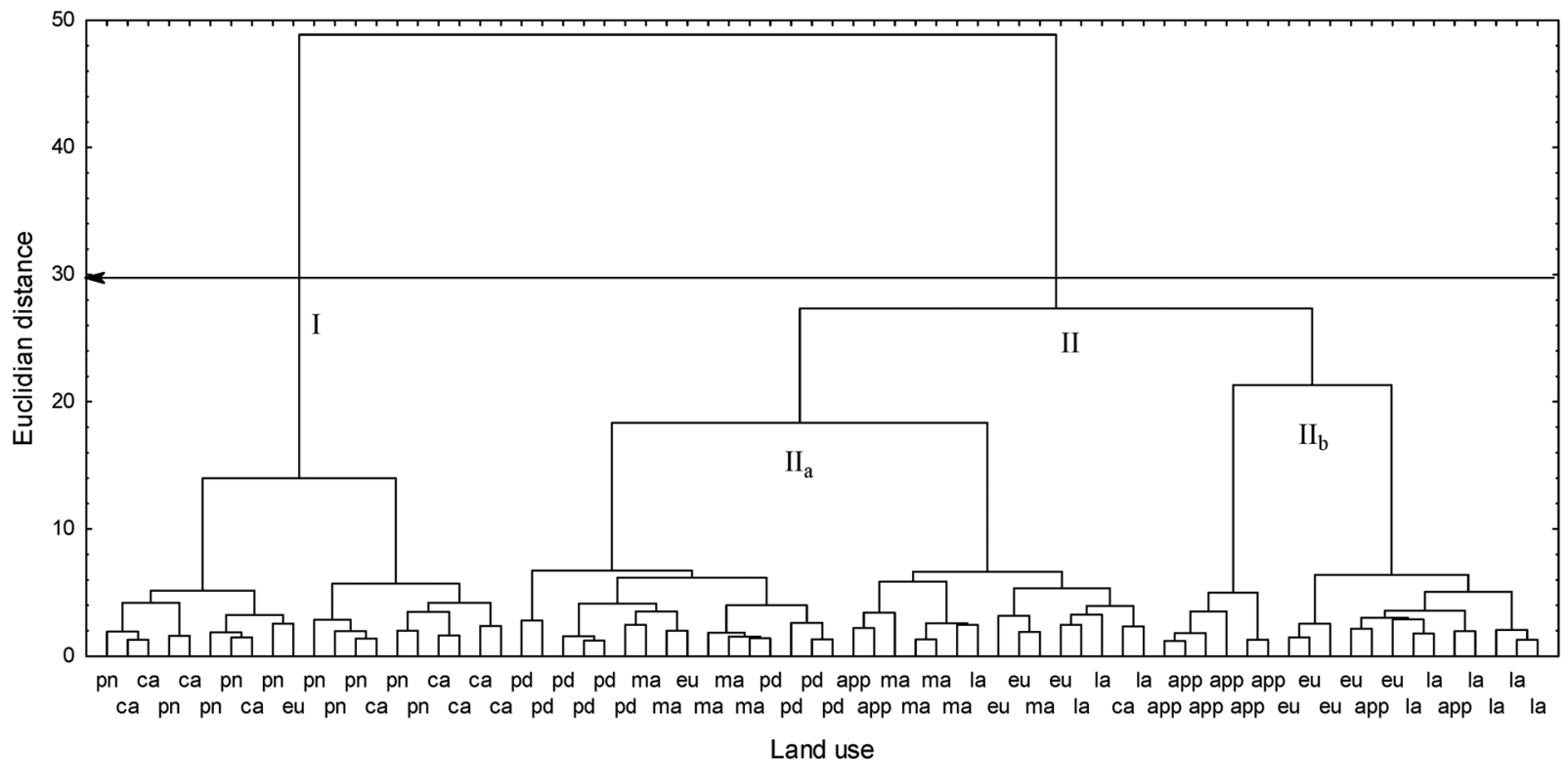

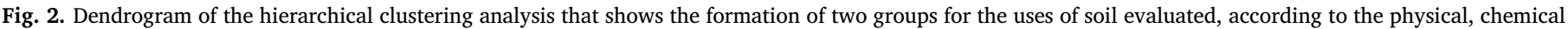
and biological attributes studied.

$\mathrm{V}=\mathrm{b}^{\mathrm{T}} \mathrm{X}^{(2)}$

where $a$ and $b$ are non-zero vectors of the coefficients of these linear combinations chosen to maximize the correlation between the variables of the canonical pair, thus ensuring that the canonical variables are not correlated to the remaining pair. $\operatorname{Min}(p, q)$ canonical pairs are obtained. The eigenvalues, their respective eigenvectors and, consequently, the correlations and canonical variables were obtained from the standardized variables, through substitution of the variances and covariances matrices by the respective correlation matrices of the original variables. Before carrying out CCA, it was verified that the cross-correlation matrix was different from zero, thus verifying that the sets of variables were independent or non-correlated. To do so, a formal test was done, which has the multivariate normal distribution of the data set, as assumed.

In addition to CCA, a clustering method was used, with the aim of discriminating the uses of the soil that presented higher similarity, and to cluster these uses, the generalized Mahalanobis distance matrix was applied. Next, the PCA method, which according to Manly (2004) describes data variation in a few indices that are linear combinations of the variables and are non-correlated between themselves, was employed. The PCA method (Eq. (5)) consisted of carrying out a rigid rotation in the original coordinate axes system, such that the new axes were in the direction of the data's highest variability, and the coefficients of the new axes are the eigenvectors of the data's sampling covariance matrix.

Let $X=\left[X_{1}, X_{2}, \ldots, X_{p}\right]^{T}$ be a random vector with $p$ attributes, sampling covariance matrix $S_{p \times p}$ with eigenvalues $\lambda_{1} \geq \lambda_{2} \geq \ldots \geq \lambda_{p} \geq 0$. Equation 9 describes the PCA method in its matrix form:

$\left[\begin{array}{c}Y_{1} \\ Y_{2} \\ \vdots \\ Y_{p}\end{array}\right]=\left[\begin{array}{cccc}e_{11} & e_{12} & \cdots & e_{1 p} \\ e_{21} & e_{22} & \cdots & e_{2 p} \\ \vdots & \vdots & \ddots & \vdots \\ e_{p 1} & e_{p 2} & \cdots & e_{p p}\end{array}\right]^{T}\left[\begin{array}{c}X_{1} \\ X_{2} \\ \vdots \\ X_{p}\end{array}\right] \Rightarrow Y=O^{T} . X$

where $e_{i}^{T}=\left(e_{i 1}, e_{i 2} \ldots, e_{i p}\right)$ is an eigenvector of dimension 1xp with $e_{i}^{T} \cdot e_{i}=1$, and $e_{i}^{T} \cdot e_{j}=0$, with $i \neq j$ for the latter condition and $i$ and $j$ ranging from 1 to $p$ for both conditions.

Finally, SEM was used to assess the effect of the physical attributes (physical attributes latent factor, PA) and the chemical attributes (chemical attributes latent factor, CA) on the variables related to the microbial activity of the soil (microbial activity latent factor, MA). SEM is a statistical technique designed to work with multiple related equations simultaneously; it provides a series of advantages compared to some more familiar methods, and offers a general structure for the linear modeling (Monecke and Leisch, 2012). SEM aims to test the validity of the theoretical models, which define causal and hypothetical relations between variables. Such relations are measured by the parameters of the model, which represent how expressive the effect of the independent variables is on the dependent variables (Marôco, 2010). The model is composed of two sub-models; one is the measurement model that correlates the attributes with their respective latent factors, and other model is the structural model that correlates the latent factors. Thus, the aim was to identify the effects of the latent factors for the physical attributes (PA) and chemical attributes (CA) of the soil on the latent factor related to the attributes of biological activity (BA) of the soil, in other words, to simultaneously identify how the soil's physical and chemical attributes influence its biological activity.

The method for estimating the parameters was through partial least squares (Wold, 1966, 1982, 1985), in which the explained variance of the latent factors is maximized by estimating the relationship between the partial models in an iterative sequence of ordinary least squares (Monecke and Leisch, 2012). This method is more advantageous in situations where the sample size is small, the data are not normally distributed, and complex models with many observed variables and the relationships are estimated (Hair et al., 2011; Ravand and Baghaei, 2016), thus being highly recommended for the data in the present study. To check the reliability of the blocks formed by the variables in study, the Dillon-Goldstein's Rho measure was applied, which must be higher than 0.7 (Tenenhaus et al., 2005). All analyses were performed using the statistical software $R$, which is free and open source $(R$ Development Core Team, 2017).

\section{Results}

The dendrogram obtained by the hierarchical clustering analysis is presented in Fig. 2. Each time that expressive changes occur in the Euclidian distance values between the recordings defined as sampling points in the uses of the soils studied, it is possible to relate the formation of groups of similar accesses, regardless of the depth of analysis $(0-0.10$ and $0.10-0.20 \mathrm{~m})$. For the 7 soil uses studied, the observed variations in the Euclidian distance values were approximately 25 and 30 (Fig. 2). The results indicated two clusters (groups I and II), and 


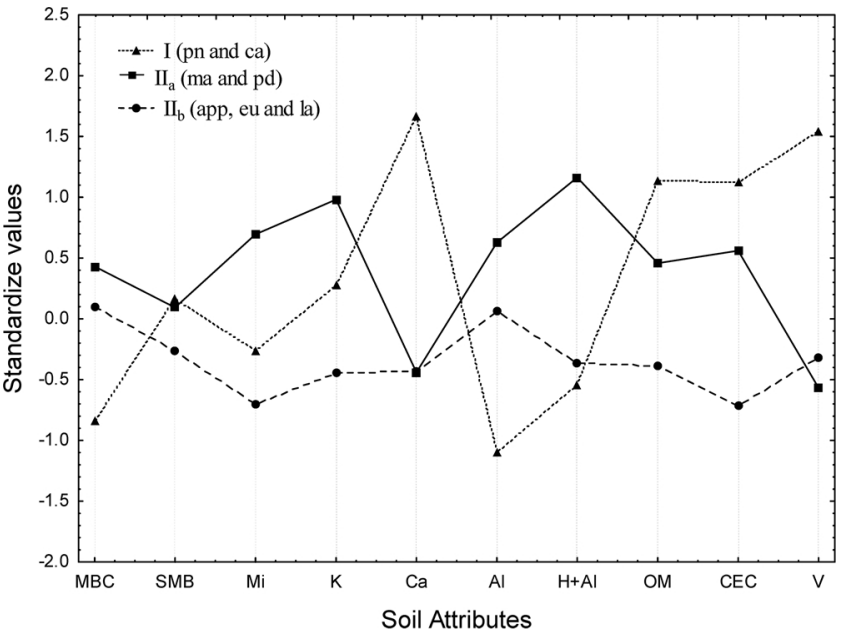

Fig. 3. Standardized means of the attributes studied in different uses of the soil, according to the non-hierarchical clustering analysis $k$-mean.

group II can be divided into two subgroups at the Euclidian distance of 25 (groups $\mathrm{II}_{\mathrm{a}}$ and $\mathrm{II}_{\mathrm{b}}$ ). In group $\mathrm{I}$, similar accesses were identified for the observations regarding the uses for forage sugarcane soil (ca) and renewed pasture (pn). In group $\mathrm{II}_{\mathrm{a}}$ the accesses gathered were mainly those related to the uses for native Amazon forest (ma) and degraded pasture (pd). On the other hand, in group $\mathrm{II}_{\mathrm{b}}$, the accesses observed were mainly those related to farming (la), permanent preservation area (app) and reforesting with eucalyptus (eu).

Fig. 3 depicts the results for the non-hierarchical clustering analysis ( $k$-means), which presents the standardized means of the physical, chemical and biological attributes of the soil, highlighting each variable's individual behavior for the groups identified ( $\mathrm{I}, \mathrm{II}_{\mathrm{a}}$ and $\mathrm{II}_{\mathrm{b}}$ ). Group I (pn and ca) presented the highest values of OM, when compared those values in the remaining groups (II). Similar results were observed for the CEC of the soil and, consequently, V. On the other hand, the no and ca (group I) areas presented the lowest values of microbial biomass carbon (MBC), indicating low retention of decomposed carbon from the vegetal material deposited in the soil, in contrast to high values of soil basal respiration. For group $\mathrm{II}_{\mathrm{a}}$ (ma and $\mathrm{pd}$ ), the highest MBC and SBR values were observed, compared to the remaining groups.

Table 1 shows the results for the principal component analysis, with the eigenvalues and correlation coefficients for verifying the formation of the groups observed in the hierarchical clustering analysis. The results indicate that $40.63 \%$ of the total variability was explained by the first principal component (PC1); the second principal component (PC2), explained $26.26 \%$ of the variability, totaling $66.89 \%$ of the variability contained in the original data. Moreover, the screeplot (Fig. 4) identified the third principal component with an eigenvalue that was higher than the unity, explaining $11.01 \%$ of the total variability of the data. The sum of the three principal components explained $77.90 \%$ of the variability contained in the original set of data. This amount of explained variation was adequate to generate the same three groups observed in the previous analysis of hierarchical clustering (Fig. 2).

The biplot graphical representation, which expressed the correlation of the variables with the principal components, is shown in Fig. 5, again indicating the formation of groups and sub-groups: $\mathrm{I}_{1} \mathrm{II}_{\mathrm{a}}$ and $\mathrm{II}_{\mathrm{b}}$. The discriminatory power of each variable within a principal component may be measured by the linear correlation coefficients between each variable and the respective principal component.

Based on the linear correlations between the attributes of the set of variables related to the microbial activity in the soil, as well as the set of physical-chemical attributes of the soil (Fig. 6), it was observed that the microbial biomass carbon presented significant positive correlations ( $\mathrm{p}<0.05$ ) with the concentrations of clay, $\mathrm{Al}$ and saturation by $\mathrm{Al}$ in
Table 1

Eigenvalues, amount of explained variance, correlation coefficients and eigenvectors between the physical, chemical and biological attributes of the different uses of the soil and the three first principal components.

\begin{tabular}{|c|c|c|c|c|c|c|}
\hline Components & \multicolumn{2}{|l|}{ PC1 } & \multicolumn{2}{|l|}{ PC2 } & \multicolumn{2}{|l|}{ PC3 } \\
\hline Eigenvalue & \multicolumn{2}{|l|}{4.06} & \multicolumn{2}{|l|}{2.62} & \multicolumn{2}{|l|}{1.10} \\
\hline $\begin{array}{l}\text { Explained } \\
\text { variance } \\
(\%)\end{array}$ & \multicolumn{2}{|l|}{40.63} & \multicolumn{2}{|l|}{26.26} & \multicolumn{2}{|l|}{11.01} \\
\hline $\begin{array}{l}\text { Cumulative } \\
\text { variance } \\
(\%)\end{array}$ & \multicolumn{2}{|l|}{40.63} & \multicolumn{2}{|l|}{66.89} & \multicolumn{2}{|l|}{77.90} \\
\hline \multicolumn{7}{|c|}{ Correlation (eigenvector) } \\
\hline MBC & $\underline{0.72}$ & $(0.36)$ & -0.21 & $(-0.13)$ & -0.03 & $(0.03)$ \\
\hline SBR & -0.13 & $(-0.06)$ & -0.30 & $(-0.19)$ & $\underline{0.81}$ & $(0.78)$ \\
\hline $\mathrm{mi}$ & 0.09 & $(0.04)$ & -0.75 & $(-0.46)$ & $\overline{0.39}$ & $(0.38)$ \\
\hline $\mathrm{K}$ & -0.13 & $(-0.06)$ & -0.70 & $(-0.43)$ & -0.01 & $(0.01)$ \\
\hline $\mathrm{Ca}$ & -0.95 & $(-0.47)$ & -0.05 & $(-0.03)$ & -0.09 & $(-0.09)$ \\
\hline $\mathrm{Al}$ & $\underline{\underline{0.88}}$ & $(0.44)$ & -0.18 & $(-0.11)$ & -0.23 & $(-0.23)$ \\
\hline $\mathrm{H}+\mathrm{Al}$ & $\overline{0.53}$ & $(0.26)$ & $-\underline{0.74}$ & $(-0.46)$ & -0.26 & $(-0.26)$ \\
\hline $\mathrm{OM}$ & -0.62 & $(-0.31)$ & $-\overline{0.59}$ & $(-0.36)$ & -0.16 & $(-0.14)$ \\
\hline CEC & -0.50 & $(-0.25)$ & -0.70 & $(-0.43)$ & -0.32 & $(-0.31)$ \\
\hline $\mathrm{V}$ & -0.95 & $(-0.47)$ & 0.13 & $(0.08)$ & -0.05 & $(-0.05)$ \\
\hline Interpretation & \multicolumn{2}{|c|}{$\begin{array}{l}\text { Ca content, soil } \\
\text { organic matter and } \\
\text { base saturation in } \\
\text { contrast with carbon } \\
\text { of the microbial } \\
\text { biomass and Al } \\
\text { content }\end{array}$} & \multicolumn{2}{|c|}{$\begin{array}{l}\text { Index of } \mathrm{K}, \mathrm{H}+\mathrm{Al} \\
\text { content, CTC and the } \\
\text { soil microporosity } \\
\text { (chemical and } \\
\text { physical interaction) }\end{array}$} & \multicolumn{2}{|c|}{$\begin{array}{l}\text { Index of soil basa } \\
\text { respiration }\end{array}$} \\
\hline
\end{tabular}

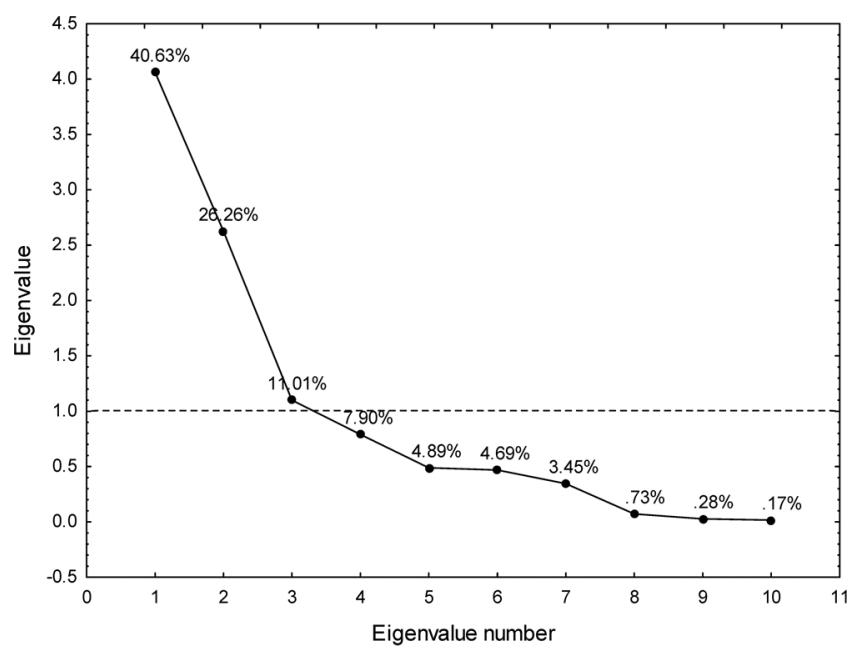

Fig. 4. Screeplot of the principal components analysis, indicating the eigenvalues that are higher than the unity, used for interpreting the results.

the soil, and significant negative correlations $(\mathrm{p}<0.05$ ) with the concentrations of silt, $\mathrm{Ca}, \mathrm{Mg}$ and organic matter in the soil. Soil microbial biomass presented significant positive correlation coefficients ( $\mathrm{p}<0.05$ ) with soil microporosity and organic matter concentration and a significant negative correlation with the macroporosity of the soil ( $\mathrm{p}<0.05$ ). Soil basal respiration (Fig. 6), in turn, presented significant positive correlation coefficients with soil microporosity and clay concentration and a significant negative correlation with the sand concentration in the soil ( $\mathrm{p}<0.05)$.

The canonical correlations are presented in Table 2, with their respective canonical $\mathrm{R}^{2}$ and the significance test performed. All canonical correlations were shown to be significant $(\mathrm{p}<0.05)$, presenting values equal to 0.7866 and 0.6267 . However, the first pair of canonical correlations explains approximately $45 \%$ of the joint variation of the variables, thus being the most important pair for the interpretation. Through the significance of the correlations presented, it may be 


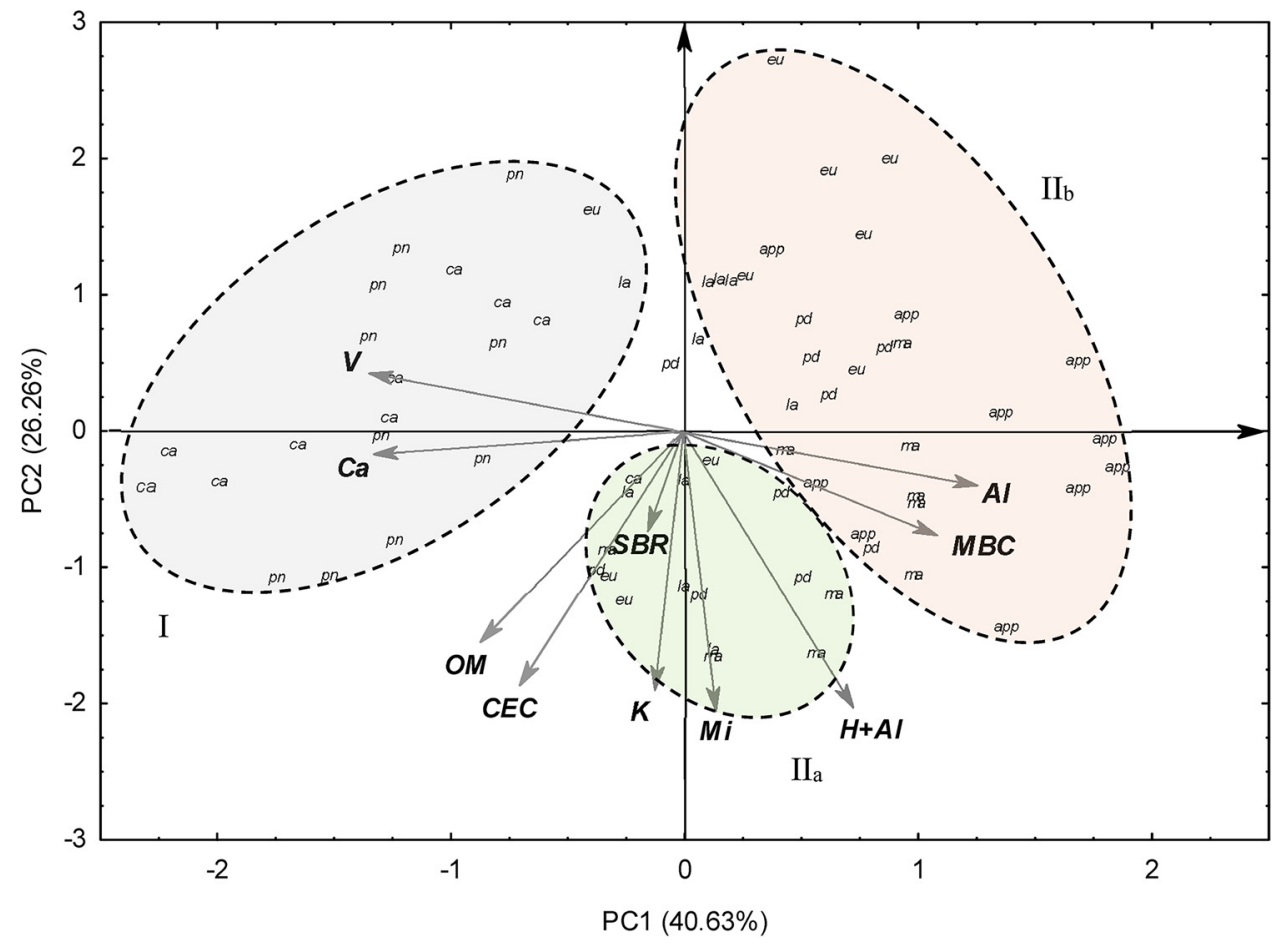

Fig. 5. Biplot graphic of the first and second principal components from the PCA with all observations in the uses of soil evaluated. $\mathrm{V}=$ saturation by bases; $\mathrm{Ca}=$ calcium concentration; $\mathrm{OM}=$ organic matter in the soil; $\mathrm{CEC}=$ capacity of exchange of cations in the soil; SBR = soil's basal respiration; SMB = soil's microbial biomass; $\mathrm{K}=$ potassium content in the soil; $\mathrm{mi}=$ microporosity; $\mathrm{H}+\mathrm{Al}=$ hydrogen + aluminum content in the soil; $\mathrm{MBC}=$ microbial biomass carbon, and $\mathrm{Al}=$ aluminum content in the soil.

concluded that the groups considered are not independent. The canonical $\mathrm{R}^{2}$ found was equal to 0.62 for the first canonical pair and 0.39 for the second canonical pair. Therefore, $U_{k}$ was the best linear combination on predicting $V_{k}$ and vice-versa, with $\mathrm{k}=1$ and 2 . Thus, the standardized values of the pair of canonical variables with the highest correlation (U1 and V1) can be seen in Fig. 7. It may be inferred that the high values of the canonical variable that presented the physical-chemical variables (V1) were associated with the high values of the canonical variable that represents the variables related to the biological attributes of the soil (U1) since they present a positive linear association.

The correlations between the original variables of a set of characteristics and the canonical component that represents them $\left(U_{k}\right.$ and $V k$ ), called canonical loadings, as well as the correlations between the variables of a set and the other canonical component, known as cross canonical loadings, are presented in Table 3. Such values are helpful for understanding the meaning of the canonical variables; the higher the absolute value of a canonical loading is, the higher the association between the original variable and its respective canonical component. It was observed that the total proportions, which were explained separately by the canonical variables $\mathrm{U}_{1}$ and $\mathrm{V}_{1}$, were equal to 50.49 and 21.57 , respectively, that is, the variable $U_{1}$ represented $50.49 \%$ of the total variation of the group of variables related to soil biological attributes, and $\mathrm{V}_{1}$ represented $21.57 \%$ of the total variation of the group of physical-chemical variables of the soil.

For the physical-chemical variables of the soil (Table 3), the highest
Table 2

Eigenvalues and canonical correlations for the attributes of the soil studied.

\begin{tabular}{|c|c|c|c|c|c|}
\hline $\begin{array}{l}\text { Pairs of } \\
\text { canonical } \\
\text { variables }\end{array}$ & $\begin{array}{l}\text { Canonical } \\
\text { correlation }\end{array}$ & $\begin{array}{l}\mathrm{R}^{2} \text { canonical } \\
\text { (eigenvalue) }\end{array}$ & $\chi^{2}$ & DF & p-value \\
\hline$(U 1, V 1)$ & 0.7866 & $\underline{0.6187}$ & 88.5239 & 28 & $<.0001$ \\
\hline$(U 2, V 2)$ & 0.6267 & 0.3927 & 30.1810 & 13 & 0.0044 \\
\hline
\end{tabular}

highlighted value significant correlation coefficients by the $\chi^{2}$ teste test at the $5 \%$ level.

canonical correlation values in modulus were observed for aluminum saturation $(-0.67)$, calcium concentration in the soil $(0.52)$, silt concentration (0.51) and magnesium concentration (0.50). The physicalchemical variables that presented higher associations with the biological component were silt, $\mathrm{Ca}, \mathrm{Mg}, \mathrm{Al}$, and saturation by aluminum. Therefore, the high values for $\mathrm{U}_{1}$ (low values for $\mathrm{MBC}$ ) were associated with low values for the attributes related to aluminum and high values for the concentrations of silt, $\mathrm{Ca}$ and $\mathrm{Mg}$.

Table 4 presents the indicators of the three latent factors considered in this study for the estimation method used for the structural equations modeling. Reliability was observed for the latent factors PA (physical attributes), CA (chemical attributes) and BA (biological attributes) because their respective values for the Dillon-Goldstein's rho were higher than 0.7. PA explained the following physical attributes: microporosity (mi), porosity (po), Sand and Clay; CA explained the chemical

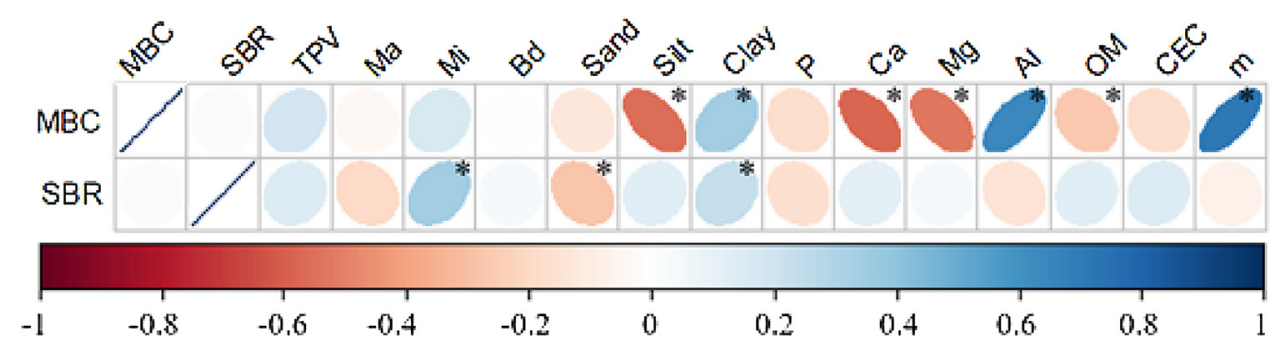

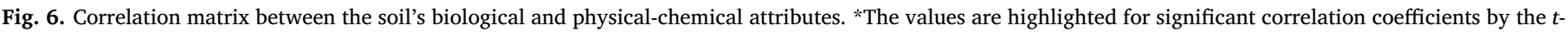
test at 5\% significance level. 


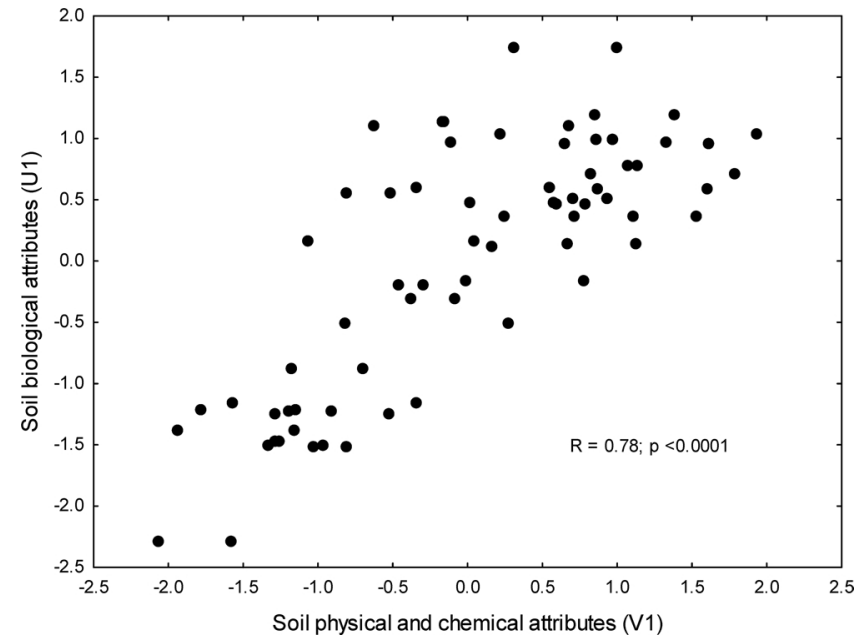

Fig. 7. Dispersion graphic of the first pair of standardized canonical variables.

Table 3

Correlations between the microbiological, physical and chemical variables of the soil from the canonical correlation analysis.

\begin{tabular}{|c|c|c|c|c|}
\hline \multirow[t]{2}{*}{ Variable } & \multicolumn{2}{|c|}{ Canonical loadings } & \multicolumn{2}{|c|}{ Canonical cross-loadings } \\
\hline & U1 & $\mathrm{U} 2$ & V1 & V2 \\
\hline MBC & -0.9778 & -0.2108 & -0.782 & -0.159 \\
\hline SBR & -0.1863 & 0.9827 & -0.223 & -0.605 \\
\hline PVTE(\%) & 50.49 & 49.51 & & \\
\hline \multirow[t]{3}{*}{ IR } & 47.74 & & & \\
\hline & \multicolumn{2}{|c|}{ Canonical loadings } & \multicolumn{2}{|c|}{ Canonical cross-loadings } \\
\hline & V1 & V2 & $\mathrm{U} 1$ & $\mathrm{U} 2$ \\
\hline TPV & -0.21 & 0.09 & -0.26 & 0.15 \\
\hline Ma & 0.08 & -0.18 & 0.10 & -0.28 \\
\hline $\mathrm{Mi}$ & -0.25 & 0.28 & -0.31 & 0.45 \\
\hline $\mathrm{Bd}$ & -0.02 & 0.04 & -0.03 & 0.06 \\
\hline Sand & 0.19 & -0.23 & 0.23 & -0.37 \\
\hline Silt & 0.51 & 0.27 & 0.63 & 0.43 \\
\hline Clay & -0.39 & 0.13 & -0.48 & 0.21 \\
\hline $\mathrm{P}$ & 0.21 & -0.11 & 0.26 & -0.17 \\
\hline $\mathrm{Ca}$ & 0.52 & 0.27 & 0.64 & 0.43 \\
\hline $\mathrm{Mg}$ & 0.50 & 0.19 & 0.61 & 0.31 \\
\hline $\mathrm{H}+\mathrm{Al}$ & -0.43 & -0.10 & -0.54 & -0.16 \\
\hline $\mathrm{OM}$ & 0.23 & 0.19 & 0.28 & 0.31 \\
\hline CEC & 0.13 & 0.19 & 0.17 & 0.30 \\
\hline $\mathrm{m}$ & -0.67 & -0.27 & -0.83 & -0.42 \\
\hline PVTE(\%) & 21.57 & 10.52 & & \\
\hline IR & 16.84 & & & \\
\hline
\end{tabular}

Table 4

Reliability and unidimensionality of the Latent Factors and evaluation of the structural equation method.

\begin{tabular}{lllllllll}
\hline Latent Factor & Mod & Variables & DG.rho & aut.1 & aut.2 & Type & $\mathrm{R}^{2}$ & VME \\
\hline PA & $\mathrm{A}$ & 4 & 0.74 & 2.24 & 0.98 & Exógeno & 0 & 0.56 \\
$\mathrm{CA}$ & $\mathrm{A}$ & 6 & 0.96 & 5.28 & 0.48 & Exógeno & 0 & 0.88 \\
$\mathrm{BA}$ & $\mathrm{A}$ & 1 & 1.00 & 1.00 & 0.00 & Endógeno & 0.50 & 1.00
\end{tabular}

PA = latent Factor Physical Attributes; CA = latent Factor Chemical Attributes; $\mathrm{BA}=$ latent Factor Attributes Microbial Activity; A = Reflective Mode (Latent Factor is the cause of Attributes); DG.Rho $=$ Rho of Dillon-Goldstein; aut.1 = eigenvalue 1; aut.2 = eigenvalue 2; VME = Average Variance Extracted.

attributes: $\mathrm{pH}, \mathrm{Ca}, \mathrm{Mg}, \mathrm{Al}$, Bases and V; and BA explained the microbial biomass carbon $(\mathrm{MBC})$ attribute; the remaining attributes presented communality lower than 0.50 in their respective latent factors, and thus, they were not considered.

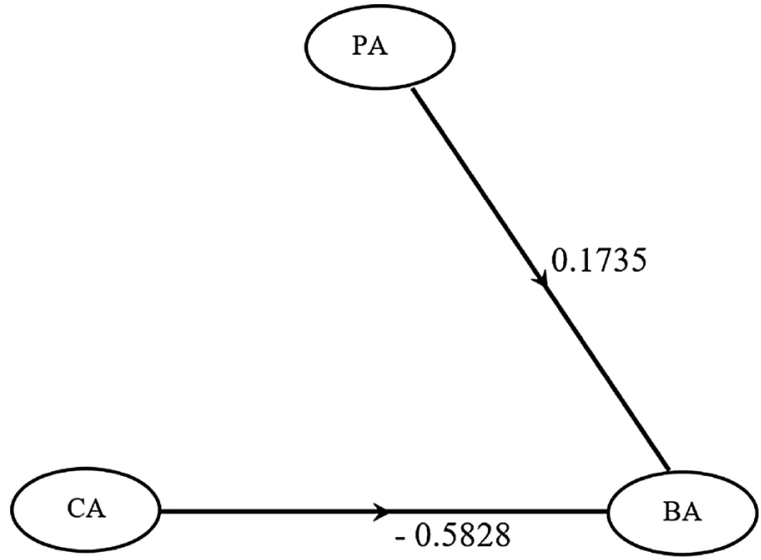

Fig. 8. Graphic representation of the Structural Model with the regression coefficients were: $\mathrm{CA}=$ Chemical attributes, $\mathrm{PA}=$ Physical attributes and $\mathrm{BA}=$ Biological attributes.

Finally, Fig. 8 depicts the graphic representation of the structural model with the regression coefficients. The coefficient that measures how expressive the effect of PA is on BA was equal to 0.1735 , whereas the effect of CA on BA was equal to -0.5828. This finding indicates that the latent factor formed by the chemical attributes $(\mathrm{pH}, \mathrm{Ca}, \mathrm{Mg}, \mathrm{Al}$, Bases, V) influenced on the latent factor microbial activity of the soil (microbial biomass carbon), in modulus by 3 times as much as the latent factor physical attributes (mi, po, Sand, Clay), which shows that soil microbial activity was controlled much more by soil chemical attributes than soil physical attributes, in the uses studied.

\section{Discussion}

The results of Fig. 2 suggest that a predominant factor for differentiating groups I and II was the improvement in soil fertility caused by liming, which aimed at correcting soil acidity, and thereby increased the concentrations of $\mathrm{Ca}$ and decreased the concentrations of $\mathrm{Al}$ in the areas pn and ca, hence increasing the concentration of exchangeable bases in the soil. In group II, not all areas presented limestone application. Additionally, in the app, eu and la areas, there were decreases in soil fertility compared to the remaining evaluated uses, as well as an increase in soil density, which was due to the decrease in total porosity. This density increase may be related to plowing of the soil and subsequent agricultural machinery traffic. These agricultural activities are often harmful, leading to a change in soil quality with different types of land use and management because vegetation removal, soil compaction, machinery use and loss of organic matter can increase the process of erosion in the long run compared erosion in areas of native vegetation (Khaledian et al., 2017; Prosdocimi et al., 2016).

In group $\mathrm{II}_{\mathrm{a}}$, the similarity between the use of degraded pasture (pd) and native amazon forest (ma) was due to the lack of plowing caused by pasture formation, which consisted of native vegetation cutting with subsequent vegetal matter burning and forage seeding, without soil tillage (Fig. 2). Therefore, dp kept the original structure of the soil and was similar to that observed in the native vegetation. Carneiro et al. (2009) observed that when working with different classes of soils (latosol and neosol) and uses (pasture, integration and annual crops) in the Cerrado, in Brazil's central-west region, non-plowing promoted the protection of organic matter. It was also noted that physical protection against microbial action caused by soil structure and grassy plant fasciculated roots decreased the oxidation process, thus identifying a group between the uses of pasture and native Cerrado in the Oxisol. For group $\mathrm{I}_{\mathrm{b}}$, it is important to stress that the similarity between these three areas was because they all had been used as pastures, providing a time for conversion to annual uses equal to 5 years (eu and app) and 1 year (la) (Balesdent et al., 2000). 
Low MBC values indicated a lower efficiency in the process of carbon conversion, usually followed by high values of soil basal respiration (SBR) (Novak et al., 2017). The carbon contained in the microbial biomass is the initial destination of this element in the process of soil transformation (Fig. 3). Therefore, MBC is considered to be an indicator of soil quality because it is sensitive to the early processes of changes in OM due soil use and management. According to Alves et al. (2011), a great number and diversity of factors (flora, microfauna, organic material deposition on the surface of the soil) in natural ecosystems favor the maintenance of chemical and biological attributes in the soil, especially in native vegetation areas or even in areas in recovery with native species. High values of SBR occurred with substantial microbiological activity (Fig. 3), which was directly related to the availability of carbon in the soil and/or microbial activity (Allen et al., 2011). Our results indicated that the highest values of SBR observed in group I (pn and ca) were associated with high values of organic matter in the soil, whereas the high values of SBR observed in group $\mathrm{II}_{\mathrm{a}}$ were related to high microbial activity.

The differences observed in the standardized means (Fig. 3) in relation to the values of calcium concentrations in the soil and $\mathrm{Al}$ and $\mathrm{Al}$ $+\mathrm{H}$ concentrations between groups I (pn and ca) and II (ma, pd, app, eu and la) were due to the operation of liming in these areas, which was performed before the experiments were carried out. Such conditions enhance soil fertility and, consequently, the production of straw by crops. Tate et al. (1991) similarly observed evidence of positive nutrient correlations, such as $\mathrm{K}, \mathrm{Ca}$ and $\mathrm{S}$ on the growth of microbial biomass in the soil.

It can be inferred that for PC1, the attributes that presented the highest correlation coefficients were (by order of importance): Ca concentration (-0.95), $\mathrm{V}(-0.95), \mathrm{Al}(0.88), \mathrm{MBC}(0.72)$ and $\mathrm{OM}(-0.62)$ (Table 1 and Fig. 5). These findings may have been due to the action of liming in the management practices studied, which influenced the chemical attributes, especially those related to soil acidity and microbial biomass carbon (Pereira et al., 2013). Novak et al. (2017) observed that biological and chemical attributes, such as MBC, SBR, Mg and $\mathrm{K}$, were the discriminatory variables in PC1 and were responsible for mainly separating the native vegetation areas (Cerrado and Mata Atlântica), with the two first principal components representing $77.42 \%$ of the variance contained in the original set of data. Such observations support the results presented in this work (Fig. 5). Nonetheless, PC2 was shown to be an index of interaction among the chemical, microbial and physical attributes of the soil. By order of importance, the variables that were responsible for discrimination in group $\mathrm{II}_{\mathrm{a}}$, native Amazon forest and degraded pasture, are mi (-0.75), $\mathrm{H}+\mathrm{Al}(-0.74), \mathrm{K}(-0.70)$ and CEC $(-0.70)$. The relationship between ma and pd was due to the similarity in relation to the biological and chemical attributes (Fig. 5).

On the other hand, the SBR presented discriminatory power only in PC3 (Fig. 5 and Table 1), with a correlation value of 0.81 . Villani et al. (2017) verified that the two first components explained $94 \%$ of the total variance and that PC1 presented high correlations with MBC and the ammonium concentration in the soil, which was mainly related to the areas of forests, agroforests and pastures. Our results support the previous statements, indicating that the microbial biomass carbon represents the efficiency of the microorganism community in the soil in transforming the carbon from the deposited material. Further, microbial biomass carbon is a variable sensitive to initial changes of $\mathrm{C}$ and is thereby related to PC1.

The conversion of the soil of pastures and natural forests for agricultural production, for high productivity purposes, causes significant changes in the physical-chemical attributes and, consequently, biological attributes of the soil. Such changes may be demonstrated by the higher sensitivity of microbial biomass carbon expressed by the significant correlation coefficients ( $\mathrm{p}<0.05$ ) with the physical-chemical attributes of the soil (Fig. 6). According to Gomes et al. (2016), who studied changes in the physical-chemical attributes of chalky soils in northeastern Brazil, the continuous use of soil in agricultural activities makes it reach a steady state that is characterized by losses in physical quality, which may be intensified in subsequent years of cultivation. Therefore, these results (Fig. 6) support those presented in this work and indicate that the proper management of soil entails the maintenance or improvement of chemical characteristics, as well as slight physical and microbiological losses in the soil.

The microbial canonical variable $\left(\mathrm{U}_{1}\right)$ presented the highest values in modulus of the canonical correlation for the microbial biomass carbon $(-0.9788)$ and soil basal respiration $(-0.1863)$, (Table 3$)$. MBC presented high and negative canonical loading, indicating that management practices with high values of MBC presented a trend of high SBR values. Soil basal respiration presented a low value of canonical correlation, which indicates low relative importance in the first canonical correlation. Maluche-Baretta et al. (2006) applied canonical correlation analysis between the groups of biological and chemical variables of the soil used for apple tree cultivation in southern Brazil and observed an inverse relationship between the MBC and SBR.

The highest canonical correlation values (Table 3 ) indicated that for areas whose aluminum concentration was high, the concentrations of aluminum and clay consequently presented lower concentrations of $\mathrm{Ca}$, $\mathrm{Mg}$ and silt, which was due to the application of limestone in the areas of ca. and np. This result indicated that there was a contrast between the concentration of aluminum, its saturation and the concentration of clay compared to the concentrations of silt, magnesium and calcium in the soil.

High canonical correlations were observed among the soil biological and physical-chemical attributes, mainly among the microbial biomass carbon and the chemical attributes of concentration and saturation of aluminum in the soil (Table 3). This result can be observed through the cross canonical loadings, in which MBC presented a higher correlation with the physical-chemical component of the soil, and this component was negatively associated with MBC. Thus, when $\mathrm{V}_{1}$ presented low values (higher concentrations of aluminum and saturation by bases, and lower values of silt, magnesium and calcium), and the MBC concentration was higher. Maluche-Baretta et al. (2006) also observed that the microbial biomass carbon was influenced by the concentrations of elements such as P, K, Ca and total organic carbon in the soil, which supports the results presented in present work. Our results indicated that the inter-group associations were established mainly by the influences of lower concentrations of MBC on low concentrations and aluminum saturation and higher values for the concentrations of silt, calcium and magnesium.

In addition, Table 3 presents the values for the redundancy analysis, indicating that $47.74 \%$ of the total variation of the biological attributes was explained by the variation of physical-chemical attributes in the soils for the evaluated uses in the first canonical correlation. On the other hand, only $16.84 \%$ of the total variation of the physical-chemical attributes was explained by the biological attributes of the soils studied in the first canonical correlation. These results again show a higher influence of the chemical attributes, mainly magnesium concentration and saturation by aluminum, on the microbial activity in the soil.

Additionally, the unidimensionality of the latent factors was confirmed (Table 4), since the first eigenvalues of each latent factor were higher than 1 , and the second eigenvalues of each latent factor were lower than 1 (Ravand and Baghaei, 2016). Furthermore, values of mean extracted variance higher than 0.5 were observed (Table 4), indicating the validity of the model. Additionally, $\mathrm{R}^{2}$ values equal to 0.50 were found, which are considered moderate for the endogenous latent factor (Hair et al., 2011). Therefore, the fitting values of the quality indicators certified the validity of the estimation method used. The structural equation (Fig. 8) modeling indicated the sensitivity of the biological attributes to the chemical variations found in the uses evaluated in the present study and supported their use for predicting changes in the environment even before significant chemical changes occur due the changes of land use and soil management (Maluche-Baretta et al., 
2006). Their changes may have indicated slightly perceptible chemical changes, which may substantially influence the biological characteristics of the soil (Rojas et al., 2016).

\section{Conclusions}

The multivariate approach used to analyze the soil's attributes was able to identify the anthropic action over the areas in natural conditions. The clustering analysis and principal components analysis together identified two groups that formed mainly due to the anthropic operations of soil preparation and liming. The use of the soil that was the closest to the natural condition (southern amazon forest) was the degraded pasture, which was mainly due to the concentrations of $\mathrm{K}$, $\mathrm{H}+\mathrm{Al}$, as well as to soil microporosity and basal respiration. Conversely, the uses of the soil that were the farthest from the natural condition were the renewed pasture and the forage sugarcane, mainly because of the calcium concentration, saturation by bases and aluminum, and microbial biomass carbon. The canonical correlation analysis highlighted the sensitivity of the microbial biomass carbon to the initial changes in the soil physical-chemical attributes, such as saturation by aluminum, calcium and magnesium concentrations in the soil, as well as concentrations of clay and silt. From the structural equations modeling, it may be inferred that the chemical attribute latent factor had an influence three times higher than that of the physical attribute latent factor over the biological attribute latent factor. Therefore, anthropic actions, especially liming, modified soil quality by reducing soil acidity, affected the floral microorganisms. This scenario also likely changed the native fungal community of the evaluated soils, which was especially expressed by microbial biomass carbon.

\section{Acknowledgements}

We are grateful to the Coordenação de Aperfeiçoamento de Pessoal de Nível Superior (CAPES) and Fundação de Amparo à Pesquisa do Estado de Mato Grosso (FAPEMAT) for their support.

\section{References}

Allen, D.E., Singh, B.P., Dalal, R.C., 2011. Soil health indicators, soil health and climate change. A review of current knowledge. In: Singh, B.P., Cowie, A.L, Chan, K.Y. (Eds.), Soil Health and Climate Change. Soil Biol. pp. 25-45.

Alves, T.D., Campos, L.L., Neto, N.E., Matsuoka, M., Loureiro, M.F., 2011. Biomass and soil microbial activity under native vegetation and different soil managements (in portuguese). Acta Scientiarum-Agron. 33, 341-347.

Balesdent, J., Chenu, C., Balabane, M., 2000. Relationship of soil organic matter dynamics to physical protection and tillage. Soil Tillage Res. 53, 215-230.

Brookes, P.C., 1995. The use of microbial parameters in monitoring soil pollution by heavy-metals. Biol. Fertil. Soils 19, 269-279.

Camargo, O.A., Moniz, A.C., Jorge, J.A., Valadares, J.M.A.S., 1986. Métodos de análise química, mineralógica e física de solos do Instituto Agronômico de Campinas. Instituto Agronômico, Campinas.

Carneiro, M.A.C., de Souza, E.D., dos Reis, E.F., Pereira, H.S., de Azevedo, W.R., 2009. Physical, chemical and biological properties of cerrado soil under different land use and tillage systems (in portuguese). R. Bras. Ci. Solo 33, 147-157.

Castilho, S.C.D., Cooper, M., Dominguez, A., Bedano, J.C., 2016. Effect of land use changes in Eastern Amazonia on soil chemical, physical, and biological attributes. Soil Sci. 181, 133-147.

Cruz, C.D., Regazzi, A.J., 1994. Modelos Biométricos Aplicados Ao Melhoramento Genético. Universidade Federal de Viçosa, Viçosa.

Doran, J.W., Parkin, T.B., 1994. Defining and assessing soil quality. In: Doran, J.W., Celeman, D.C., Bezdicek, D.F., Stewart, B.A. (Eds.), Defining Soil Quality for a Sustainable Environment. Soil Science Society of America, Madison, pp. 212.

EMBRAPA, 1997. Manual De Métodos De Análise De Solo, 2 ed. Ministério da Agricultura e do Abastecimento / EMBRAPA-CNPS, Brasília.

Fonseca, G.C., Carneiro, M.A.C., Costa, A.Rd., Oliveira, G.Cd., Balbino, L.C., 2007. Physical, chemical and biological attributes of dystrophic red oxisol under two crop rotations. Pesqui. Agropecuãiria Trop. 37, 22-30.

Gomes, J.B.V., Fernandes, M.F., Pacheco, E.P., Barreto, A.C., Norton, L.D., Curi, N., 2016 Calcareous soils in the Northeastern of Brazil: alterations of attributes from different land use history. Soil Tillage Res. 155, 27-34.

Gong, L., Ran, Q.Y., He, G.X., Tiyip, T., 2015. A soil quality assessment under different land use types in Keriya river basin, Southern Xinjiang, China. Soil Tillage Res. 146, 223-229.

Hair, J.F., Anderson, R.E., Tatham, R.L., Black, W., 2005. Multivariate Data Analysis. Prentice Hall, Richmond.

Hair, J.F., Ringle, C.M., Sarstedt, M., 2011. PLS-SEM: indeed a silver bullet. J. Mark. Theory Pract. 19, 139-152.

Johnson, R.A., Wichern, D.W., 2002. Applied Multivariate Statistical Analysis. Prentice Hall, New Jersey.

Khaledian, Y., Kiani, F., Ebrahimi, S., Brevik, E.C., Aitkenhead-Peterson, J., 2017. Assessment and monitoring of soil degradation during land use change using multivariate analysis. Land Degrad. Dev. 28, 128-141.

Kiehl, E.J., 1979. Manual De Edafologia: Relação Solo-água-planta. Agronômica Ceres, São Paulo.

Maluche-Baretta, C.R.D., do Amarante, C.V.T., Klauberg, O., 2006. Multivariate analysis of soil attributes of apple orchards under conventional and organic production systems (in portuguese). Pesq. agropec. bras. 41, 1531-1539.

Manly, B.F.J., 2004. Multivariate Statistical Methods: A Primer. Chapman \&amp; Hall/ CRC, Boca Raton.

Marôco, J., 2010. Análise de equações estruturais: Fundamentos teóricos, software e aplicações. Report Number, Pero Pinheiro.

Monecke, A., Leisch, F., 2012. semPLS: Structural Equation Modeling Using Partial Least Squares. J. Stat. Softw. 48, 1-32.

Nazmi, L., 2013. Modeling for relationships between soil properties and yield components of wheat using multiple linear regression and structural equation modeling. Adv. Environ. Biol. 7, 235-242.

Novak, E., Carvalho, L.A., Santiago, E.F., Portilho, I.I.R., 2017. Chemical and microbiological attributes under different soil cover. Cerne 23, 19-30.

Pereira, J.D., Baretta, D., Bini, D., Vasconcellos, R.L.D., Cardoso, E., 2013. Relationships between microbial activity and soil physical and chemical properties in native and reforested Araucaria angustifolia forests in the state of sao paulo, brazil. R. Bras. Ci. Solo $37,572-586$.

Pragana, R.B., Ribeiro, M.R., Nobrega, J.C.A., Ribeiro, M.R., da Costa, J.A., 2012. Physical quality of oxisols under no-tillage in the savanna region of piaui. R. Bras. Ci. Solo 36, 1591-1600.

Prosdocimi, M., Jordan, A., Tarolli, P., Keesstra, S., Novara, A., Cerda, A., 2016. The immediate effectiveness of barley straw mulch in reducing soil erodibility and surface runoff generation in Mediterranean vineyards. Sci. Total Environ. 547, 323-330.

R Development Core Team, 2017. A Language and Environment for Statistical Computing. R Foundation for Statistical Computing, Vienna, Austria.

Ravand, H., Baghaei, P., 2016. Partial least squares structural equation modeling with R. Practical assessment. Res. Eval. 21, 1-16.

Reichert, J.M., Kaiser, D.R., Reinert, D.J., Riquelme, U.F.B., 2009. Temporal variation of soil physical properties and root growth of black beans in four management systems. Pesq. agropec. bras. 44, 310-319.

Rojas, J.M., Prause, J., Sanzano, G.A., Arce, O.E.A., Sánchez, M.C., 2016. Soil quality indicators selection by mixed models and multivariate techniques in deforested areas for agricultural use in NW of Chaco, Argentina. Soil Tillage Res. 155, 250-262.

Sanabria, C., Dubs, F., Lavelle, P., Fonte, S.J., Barot, S., 2016. Influence of regions, land uses and soil properties on termite and ant communities in agricultural landscapes of the Colombian Llanos. Eur. J. Soil Biol. 74, 81-92.

Silva, E.E., Azevedo, P.H.S., De-Polli, H., 2007a. Determinação Da Respiração Basal (RBS) E Quociente Metabólico Do Solo (qCO2). Embrapa Agrobiologia, Seropédica.

Silva, E.E., Azevedo, P.H.S., De-Polli, H., 2007b. Determinação Do Carbono Da Biomassa Microbiana Do Solo (BMS-C). Embrapa Agrobiologia, Seropédica.

Tate, K.R., Ross, D.J., Ramsay, A.J., Whale, K.N., 1991. Microbial biomass and bacteria in 2 pasture soils - an assessment of measurement procedures, temporal variations, and the influence of $\mathrm{p}$ fertility status. Plant Soil 132, 233-241.

Tenenhaus, M., Vinzi, V.E., Chatelin, Y.-M., Lauro, C., 2005. PLS path modeling. Comput. Stat. Data Anal. 48, 159-205.

Villani, F.T., Ribeiro, G.A.A., Villani, E.Md.A., Teixeira, W.G., Moreira, F.Md.S., Miller, R., Alfaia, S.S., 2017. Microbial Carbon, Mineral-N and Soil Nutrients in Indigenous Agroforestry Systems and Other Land Use in the upper Solimões Region, Western Amazonas State, Brazil. Agric. Sci. 8, 657-674.

Wold, H., 1966. Estimation of principal components and related models by iterative least squares. In: Krishnajah, P.R. (Ed.), Multivariate Analysis. Academic Press, New York, pp. 391-420.

Wold, H., 1982. Soft modeling: intermediate between Traditional Model Building and data analysis. Math. Stat. 6, 333-346.

Wold, H., 1985. Partial least squares. In: Kotz, Samuel, Read, Campbell B., Balakrishnan, N., Vidakovic, Brani (Eds.), Encyclopedia of Statistical Sciences. John Wiley \& Sons, New York, pp. 581-591. 